Article

\title{
Neuroprotective Effects of $\beta$-Caryophyllene against Dopaminergic Neuron Injury in a Murine Model of Parkinson's Disease Induced by MPTP
}

\author{
Juan M. Viveros-Paredes ${ }^{1}$, Rocio E. González-Castañeda ${ }^{2}$, Juerg Gertsch ${ }^{3}$, \\ Veronica Chaparro-Huerta ${ }^{4}$, Rocio I. López-Roa ${ }^{1}$, Eduardo Vázquez-Valls ${ }^{5}$, Carlos Beas-Zarate ${ }^{6}$, \\ Antoni Camins-Espuny ${ }^{7,8}$ and Mario E. Flores-Soto ${ }^{1,2, *}$ \\ 1 Departamento de Farmacobiología CUCEI, Universidad de Guadalajara, 44430 Guadalajara, Mexico; \\ jviveros99@hotmail.com (J.M.V.-P.); rlopezroa@gmail.com (R.I.L.-R.) \\ 2 Laboratorio de Microscopía de Alta Resolución, Departamento de Neurociencias, Centro Universitario de \\ Ciencias de la Salud, Universidad de Guadalajara, 44340 Guadalajara, Mexico; roglezca@yahoo.com.mx \\ 3 Institute of Biochemistry and Molecular Medicine, NCCR Trans Cure, University of Bern, CH-3012 Bern, \\ Switzerland; gertsch@ibmm.unibe.ch \\ 4 Laboratorio de Neurobiología Celular y Molecular, Centro de Investigación Biomédica de Occidente (CIBO), \\ Instituto Mexicano del Seguro Social, 44421 Guadalajara, Mexico; veronicach73@mail.com \\ 5 Laboratorio de Inmunodeficiencias y Retrovirus Humanos, Centro de Investigación Biomédica de Occidente, \\ Instituto Mexicano del Seguro Social, 44421 Guadalajara, Mexico; evazquez@cencar.udg.mx \\ 6 Laboratorio de Regeneración y Desarrollo Neural, Instituto de Neurobiología, Departamento de Biología \\ Celular y Molecular, CUCBA, Universidad de Guadalajara, 44340 Guadalajara, Mexico; \\ carlosbeas55@gmail.com \\ 7 Unitat de Farmacologia i Farmacognòsia, Facultat de Farmàcia i Ciencias de l'Alimentació, Universitat de \\ Barcelona, 08028 Barcelona, Spain; camins@ub.edu \\ 8 Biomedical Research Networking Center in Neurodegenerative Diseases (CIBERNED), 28031 Madrid, Spain \\ * Correspondence: mario.flores@hotmail.es; Tel.: +52-(33)-1378-5900 (ext. 7526)
}

Received: 14 June 2017; Accepted: 3 July 2017; Published: 6 July 2017

\begin{abstract}
Parkinson's disease (PD) is one of the most common neurodegenerative disorders and is characterized by the loss of dopaminergic neurons in the substantia nigra (SN). Although the causes of PD are not understood, evidence suggests that its pathogenesis is associated with oxidative stress and inflammation. Recent studies have suggested a protective role of the cannabinoid signalling system in PD. $\beta$-caryophyllene (BCP) is a natural bicyclic sesquiterpene that is an agonist of the cannabinoid type 2 receptor (CB2R). Previous studies have suggested that BCP exerts prophylactic and/or curative effects against inflammatory bowel disease through its antioxidative and/or anti-inflammatory action. The present study describes the neuroprotective effects of BCP in a 1-methyl-4-phenyl-1,2,3,6-tetrahydropyridine (MPTP)-induced murine model of PD, and we report the results of our investigation of its neuroprotective mechanism in neurons and glial cells. In the murine model, BCP pretreatment ameliorated motor dysfunction, protected against dopaminergic neuronal losses in the SN and striatum, and alleviated MPTP-induced glia activation. Additionally, $\mathrm{BCP}$ inhibited the levels of inflammatory cytokines in the nigrostriatal system. The observed neuroprotection and inhibited glia activation were reversed upon treatment with the CB2R selective antagonist AM630, confirming the involvement of the CB2R. These results indicate that $\mathrm{BCP}$ acts via multiple neuroprotective mechanisms in our murine model and suggest that $\mathrm{BCP}$ may be viewed as a potential treatment and/or preventative agent for PD.
\end{abstract}

Keywords: $\beta$-caryophyllene; Parkinson's disease; MPTP; microglial activation 


\section{Introduction}

Parkinson's disease (PD) is a common neurodegenerative disorder characterized by the progressive degeneration of nigrostriatal dopaminergic (DA) neurons. The most prominent biochemical changes in PD involve the reduction of striatal dopamine levels, which may result in abnormal motor behaviour, including resting tremors, rigidity, and bradykinesia [1]. The incidence of PD increases with age [2], and PD affects approximately $6 \%$ of those over the age of 65 . Even in the beginning stages, PD can lead to significant dysphagia that negatively impacts the quality of life [3]. The primary neurodegeneration trigger remains uncertain; however, several pathophysiological mechanisms have been implicated, including ageing, highly dense microglia in the substantia nigra (SN), inflammation, oxidative/nitrosative stress, abnormal protein deposits, and decreased neurotrophic factors [4]. These mechanisms lead to microglia activation, which, in turn, favours an oxidative and inflammatory environment that is facilitative of neuronal death [5]. In the substantia nigra of PD patients and in 1-methyl-4-phenyl-1,2,3,6-tetrahydropyridine (MPTP) models of PD, key enzymes involved in reactive oxygen species (ROS) production, such as microglia NAPDH oxidase, are upregulated in damaged areas and contribute to DA neuronal cell death [6]. In addition, proinflammatory cytokines, such as IL-1 $\beta$ and TNF- $\alpha$, are augmented in PD patients $[7,8]$ and participate in DA neuronal cell death in the MPTP model of PD [9,10].

Recent studies have suggested that the cannabinoid signalling system plays a protective role in PD. For example, during PD, endocannabinoids accumulate, cannabinoid receptors are upregulated, and treatment with cannabinoid agonists, either endocannabinoids or phytocannabinoids/synthetic cannabinoids, protects nigrostriatal dopaminergic neurons against MPTP neurotoxicity by inhibiting microglia activation [11].

The effects of cannabinoids are mainly mediated by the action of G-protein-coupled type 1 cannabinoid receptors (CB1Rs) and type 2 cannabinoid receptors (CB2Rs). CB2Rs were initially thought to be expressed primarily in activated microglia and peripheral immune cells where they regulate cytokine/chemokine production and cell migration [12]. Numerous in vitro studies have shown that microglia activation of the CB2R inhibits the release of proinflammatory cytokines [13] and increases the release of anti-inflammatory cytokines. On the other hand, in vivo studies have shown that pharmacological activation of the CB2R can reduce the activation of microglia cells and inhibit dopaminergic cell death in the substantia nigra in PD models [14]. Moreover, genetic studies have supported these pharmacological findings, with CB2R knock-out mice displaying increased microglia activation, neural pathology and functional deficits in models of PD [15]. Post-mortem studies of human patients with PD have revealed that the CB2R levels were elevated in microglial cells in the substantia nigra of PD patients [16]. Although a great amount of evidence has indicated the presence of functional CB2Rs in the central nervous system (CNS), potential neuroprotective properties of these CB2Rs and the molecular mechanisms underlying the effects associated with their activation during PD are not yet understood. In addition, an important advantage of compounds that specifically activate CB2R is that they do not cause any of the effects frequently associated with psychotropic cannabinoids that activate the CB1R, indicating that can be safe and well-tolerated in clinical applications.

$\beta$-Caryophyllene (BCP) is a natural bicyclic sesquiterpene isolated from clove leaf oil, clove stem oil, cinnamon leaf oil, and pine oil fractions. It has been used as a flavouring agent and as a fragrance ingredient since the 1930s [17]. Further, it has been granted the generally recognized-as-safe (GRAS) status by the Flavour and Extract Manufacturers Association and is approved by the U.S. FDA for use in food because of its low toxicity. This compound is known to be antimicrobial [18], antioxidant [19] and anticarcinogenic [20], and it also possesses properties that enhance skin penetration [21]. Specifically, essential oils that have BCP as a major component (30.6\%) have shown obvious anti-inflammatory activity against carrageenan- and prostaglandin E (PGE) 1-induced oedema in rats as well as antiarthritic activity [22,23]. Recently, it has been demonstrated that BCP exerts prophylactic and/or curative effects against inflammatory bowel disease through its antioxidative and/or anti-inflammatory action [24]. Like other CB2R agonists, trans-caryophyllene inhibits inflammation, oedema formation, 
and the expression of inflammatory mediators in vitro and in vivo. Thus, we hypothesized that BCP may improve motor behaviour and prevent the loss of nigrostriatal dopaminergic neurons by inhibiting brain inflammation and oxidative stress in an experimental model of Parkinson's disease. However, the influence of BCP on PD has not yet been explored.

\section{Results}

2.1. Motor Behavioural Test: $\beta$-Caryophyllene Inhibits Chronic MPTP-Induced Defects in Motor Coordination via the CB2 Receptor

\subsubsection{Pole Test Analysis}

The effects of $\mathrm{BCP}$ administered both intraperitoneally and orally on mouse motor function were assessed with the pole test. Mice were examined under baseline conditions prior to the administration of MPTP. Deficits in motor coordination were clearly observed in the MPTP-treated mice, with the most severe motor function impairment being $16.5 \pm 1.7 \mathrm{~s}$ required for the mice to turn at the top of the pole and climb down in comparison to that of the control group. Administration of $10 \mathrm{mg} / \mathrm{kg} \mathrm{BCP}$ both orally and intraperitoneally prior to the administration of MPTP significantly showed a recovery effect on the MPTP-induced movement impairment (intraperitoneal: $7.3 \pm 1.5 \mathrm{~s}$; oral: $5.7 \pm 1.8 \mathrm{~s}$ ). AM630 (3 mg/kg, i.p.) significantly reversed the BCP-induced improvement in the pole test $(p<0.01)$. In the groups treated only with BCP and AM630, no statistically significant changes compared to the control group were observed (Figure 1).

A

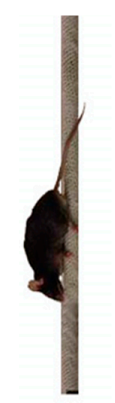

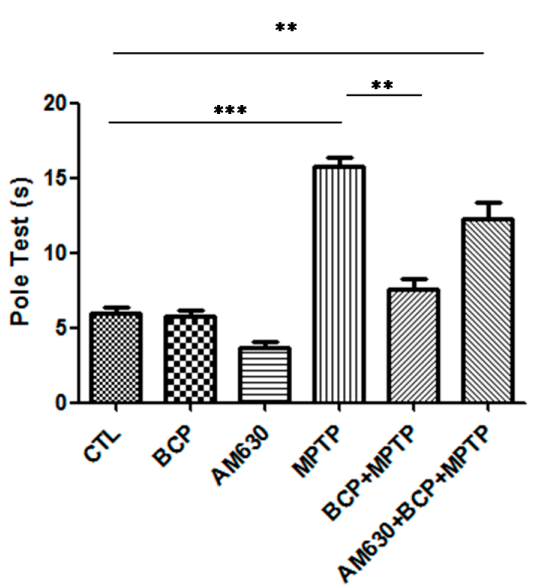

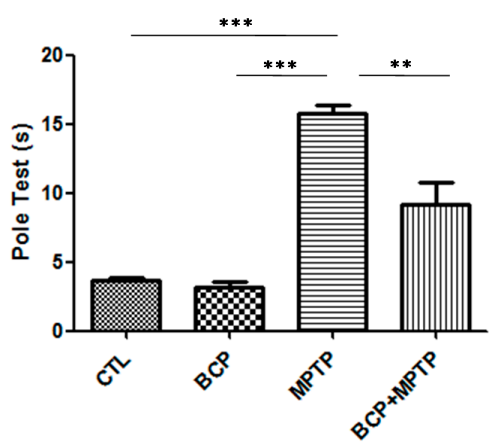

Figure 1. The pole test. The protective effects of BCP administered both intraperitoneally (A) and orally (B) against MPTP-induced behavioural impairment in mice. MPTP-treated mice displayed a significant increase in the total time required to traverse the pole $3 \mathrm{~d}$ post lesion relative to that of the CTL-injected mice. The data are presented as mean \pm SEM of six individual experiments. Intraperitoneal: ${ }^{* * *} p<0.001$, CTL vs. MPTP. ${ }^{* *} p<0.01$, MPTP vs. BCP + MPTP. ${ }^{* *} p<0.01$, CTL vs. AM630 + BCP + MPTP treatment. Oral: ${ }^{* * *} p<0.001$, CTL vs. MPTP. ${ }^{* *} p<0.01$, MPTP vs. BCP + MPTP. *** $p<0.001, \mathrm{BCP}$ vs. MPTP treatment.

\subsubsection{Gait Test Analysis}

On the other hand, a shortened shift stride is considered a symptom of Parkinson's disease. In the group treated with MPTP, decreased stride length relative to that of the control group was observed. However, in the groups treated with BCP $(10 \mathrm{mg} / \mathrm{kg}$, i.p. $)$ administered both orally and intraperitoneally prior to MPTP administration, an increase in stride length compared to that of the MPTP-treated group was observed. AM630 (3 mg/kg, i.p.) significantly reversed the BCP-induced improvement in the gait test $(p<0.01)$. In the groups treated with only BCP or AM630, no statistically significant changes were observed compared to the control group (Figure 2). 
A

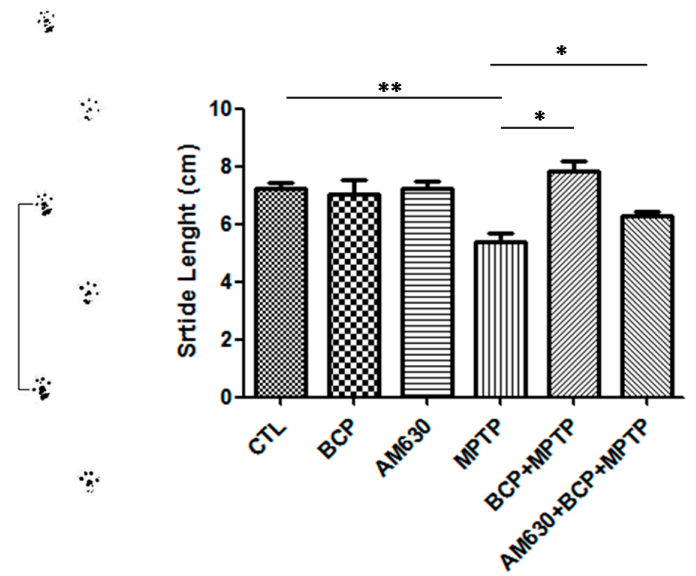

B

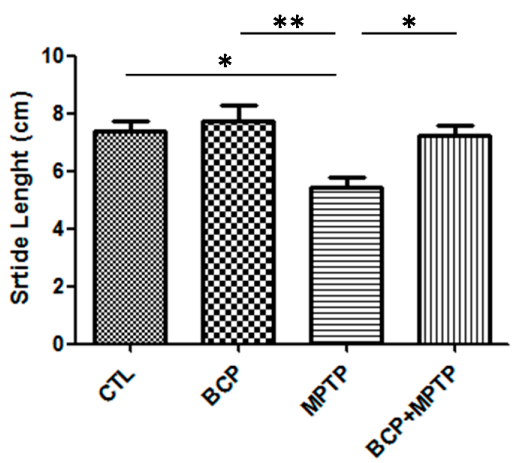

Figure 2. The gait test. The protective effects of BCP administered both intraperitoneally (A) and orally (B) against MPTP-induced behavioural impairment in mice. The MPTP-lesioned mice exhibited a significant decrease in the average stride length 3 days post-lesion compared to that of the CTL-treated mice. The data are presented as the mean \pm SEM of six individual experiments. Intraperitoneal: ${ }^{* *} p<0.01, \mathrm{CTL}$ vs. MPTP. ${ }^{*} p<0.05, \mathrm{MPTP}$ vs. $\mathrm{BCP}+\mathrm{MPTP} .{ }^{*} p<0.05, \mathrm{MPTP}$ vs. AM630 + BCP + MPTP treatment. Oral: ${ }^{*} p<0.05$, CTL vs. MPTP. ${ }^{* *} p<0.01$, BCP vs. MPTP. ${ }^{*} p<0.05$, MPTP vs. BCP + MPTP treatment.

\subsubsection{Beam Test}

Motor defects of animals from each of the treatment groups to navigate the balance beam was evaluated to study this aspect. Figure 3 shows that the average time it took the control mice to cross the beam was $8 \mathrm{~s}$, while mice exposed to MPTP took $11.8 \mathrm{~s}$ to cross the beam, which was statistically significant compared to that of the group control.

A

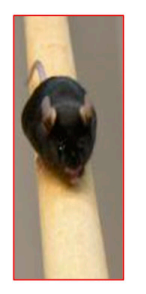

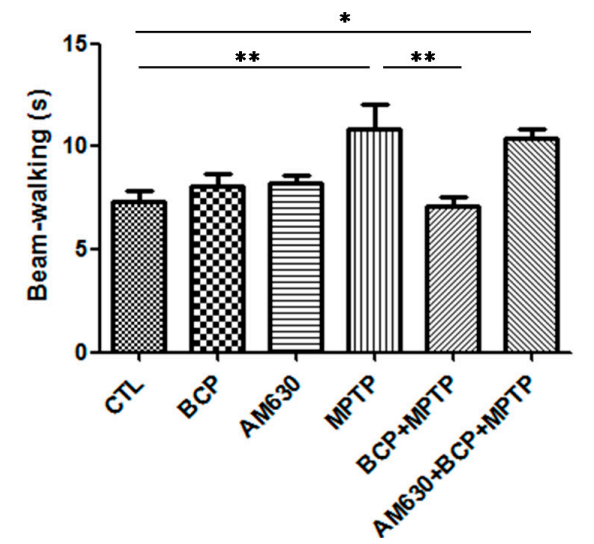

B

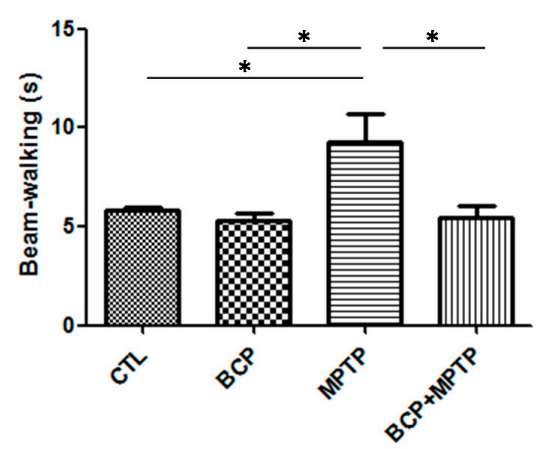

Figure 3. The beam test. The protective effects of BCP administered both intraperitoneally (A) and orally (B) against MPTP-induced behavioural impairment in mice. MPTP-lesioned mice exhibited a significant decrease in the average time required to cross the beam 3 days post-lesion compared to that of the CTL-treated mice. The data are presented as the mean \pm SEM of six individual experiments. Intraperitoneal: ${ }^{* *} p<0.01, \mathrm{CTL}$ vs. MPTP. ${ }^{* *} p<0.01, \mathrm{MPTP}$ vs. $\mathrm{BCP}+\mathrm{MPTP} .{ }^{*} p<0.05, \mathrm{CTL}$ vs. AM630 + BCP + MPTP treatment. Oral: ${ }^{*} p<0.05$, CTL vs. MPTP. ${ }^{*} p<0.05$, BCP vs. MPTP. ${ }^{*} p<0.05$, MPTP vs. BCP + MPTP treatment. 
In contrast, in the groups treated with $\mathrm{BCP}(10 \mathrm{mg} / \mathrm{kg}$, i.p.) administered both orally and intraperitoneally prior to the administration of MPTP, a decrease in the time it took the animals to cross the beam of $7.5 \mathrm{~s}$ intraperitoneally and $7.5 \mathrm{~s}$ orally was observed, which was statistically significant with respect to that of the MPTP treatment group. AM630 (3 mg/ $\mathrm{kg}$, i.p.) significantly reversed the BCP-induced improvement in the beam test $(p<0.01)$. In the groups treated with only BCP or AM630, no statistically significant changes were observed compared to the control group.

\section{2. $\beta$-Caryophyllene Prevents Chronic MPTP-Induced Dopaminergic Neuron Loss in the SNpc and STR via the CB2 Receptor}

$\mathrm{TH}$-immunoreactivity was measured in the SNpc and STR to explore the effects of BCP on the MPTP-induced degeneration of dopaminergic neurons. Treatment with MPTP significantly reduced the number of TH-IR neurons by $74 \%$ compared with that of the control mice. However, in mice treated with BCP $(10 \mathrm{mg} / \mathrm{kg}$, i.p.) and MPTP, the number of dopaminergic neurons was reduced by only $18.4 \pm 3.4 \%$ compared with that of the control. To determine whether the protective effect of BCP against MPTP-induced dopaminergic neuronal degeneration was mediated by $C B 2 R$, mice were pretreated with the CB2R selective antagonist $A M 630(3 \mathrm{mg} / \mathrm{kg}$, i.p.) $30 \mathrm{~min}$ prior to $B C P$ administration. AM630 significantly reversed the protective effect of $\mathrm{BCP}$, as evidenced by a reduction in the number of dopaminergic neurons $(79 \pm 1.7 \%)$ compared with that of the control mice $(p<0.01$; Figure 4). Systemic administration of BCP or AM630 by themselves did not significantly affect the number of TH-immunoreactive cells ( $p<0.05$ compared with that of the controls).

A

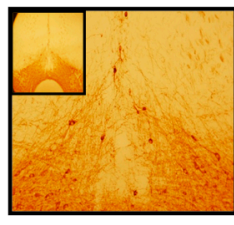

Control

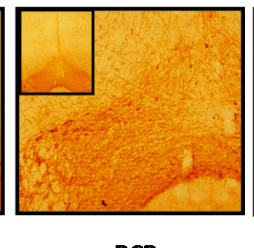

BCP

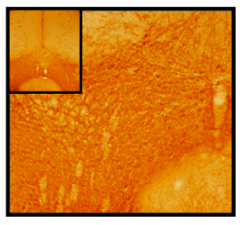

AM630

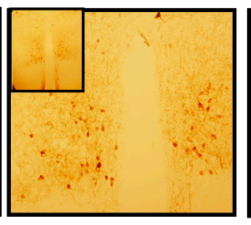

MPTP

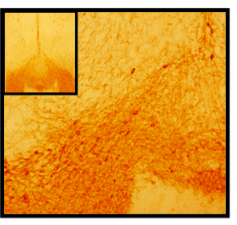

BCP+ MPTP

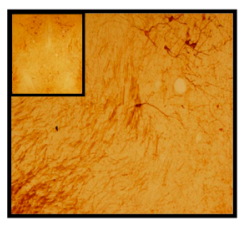

AM630+BCP+MPTP

B

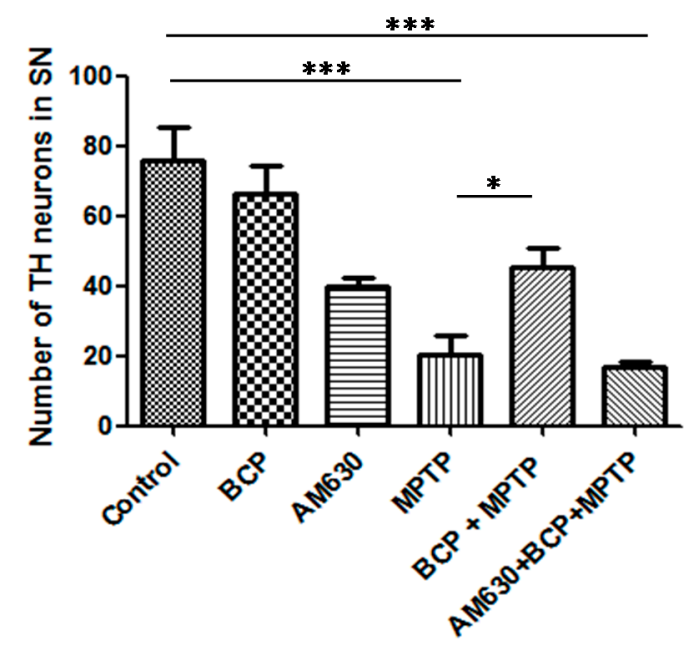

Figure 4. $\mathrm{BCP}$ treatment attenuates the MPTP-induced nigrostriatal dopaminergic neuronal damage. C57BL/ 6 mice were treated with MPTP for 5 days (30 mg/ $\mathrm{kg}$, i.p.). The mice were sacrificed on the 3rd day after MPTP injection after being subjected to behavioural tests. Photomicrographs of representative $\mathrm{SN}$ (A) sections stained with an antibody against TH. Reduced activity of TH-neurons was observed in the MPTP-treated mice, which was partially prevented by treatment with BCP. The number of TH-positive neurons in the SN (B) was expressed as the mean \pm SEM of six individual experiments. ${ }^{* * *} p<0.001, \mathrm{CTL}$ vs. MPTP treatment. ${ }^{*} p<0.05$, MPTP treatment vs. BCP + MPTP treatment. ${ }^{* *} p<0.001, \mathrm{CTL}$ vs. AM630 + BCP + MPTP treatment. 
Densitometric analysis showed that the number of TH-positive fibres in the STR was decreased by $61 \%$ after MPTP administration compared to that of the control group $(p<0.001)$. By contrast, mice treated with BCP (10 mg/kg, i.p.) and MPTP displayed an increased number of TH-positive fibres in the STR compared to that of the MPTP group $(p<0.001)$. In mice treated with BCP and MPTP, the number of TH-positive fibres was reduced by only $17.4 \pm 5.4 \%$ compared with that of the control mice. AM630 significantly reversed the protective effect of BCP, as evidenced by a reduction in the number of TH-positive fibres in the STR $(47.7 \pm 1.7 \%)$ compared with that of the control mice $(p<0.05$; Figure 5). Systemic administration of BCP did not significantly affect the number of TH-positive fibres.
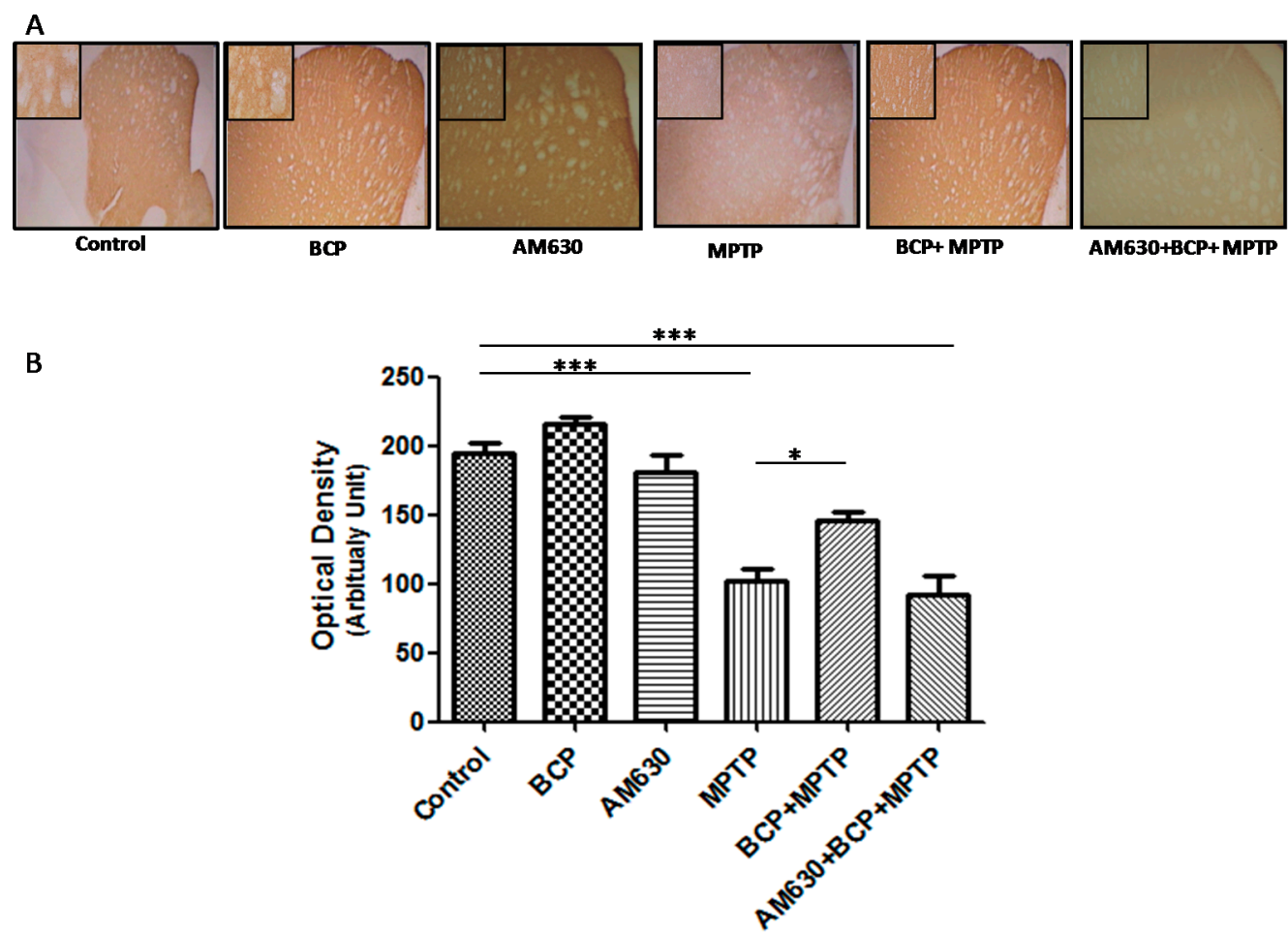

Figure 5. BCP treatment attenuates MPTP-induced nigrostriatal dopaminergic neuronal damage. C57BL/ 6 mice were treated with MPTP for 5 days (30 mg/ $\mathrm{kg}$, i.p.). The mice were sacrificed on the 3rd day after MPTP injection after being subjected to behavioural tests. Photomicrographs of representative STR (A) sections stained with an antibody against TH. Reduced activity of TH-neurons was observed in the MPTP-treated mice, which was partially prevented by treatment with BCP. The number of TH-positive fibres in the STR (B) was expressed as the mean \pm SEM of six individual experiments. ${ }^{* * *} p<0.001, \mathrm{CTL}$ vs. MPTP treatment. ${ }^{*} p<0.05$, MPTP treatment vs. BCP + MPTP treatment. ${ }^{* * *} p<0.001, \mathrm{CTL}$ vs. AM630 + BCP + MPTP treatment.

\section{3. $\beta$-Caryophyllene Inhibits Chronic MPTP-Induced Astrocyte and Microglia Activation in the SNpc and} STR via the CB2 Receptor

To evaluate the effects of BCP on astrocyte and microglia activation, the astrocyte marker GFAP and the microglia marker IBA-1 were detected by immunohistochemistry. Chronic administration of MPTP (30 mg/kg, i.p.) markedly activated astrocytes (Figure 6) and microglia (Figure 7) in the mouse $\mathrm{SNpc}$, as evidenced by significantly increased numbers of GFAP-IR cells (163.2\% compared with that of the control mice) and IBA-1-IR cells (46.2\% compared with that of the control mice). 
A

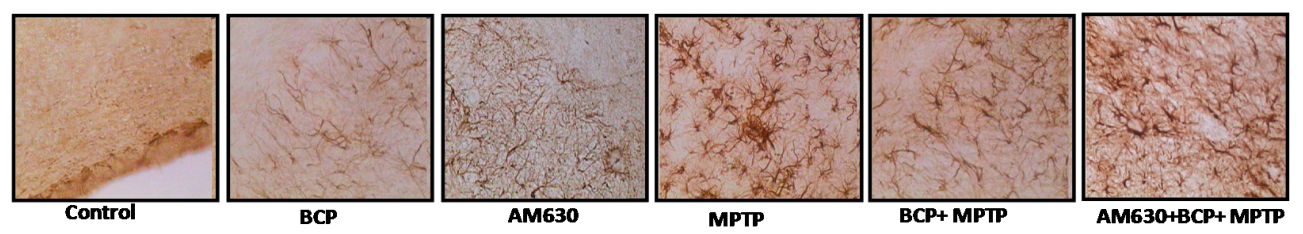

B

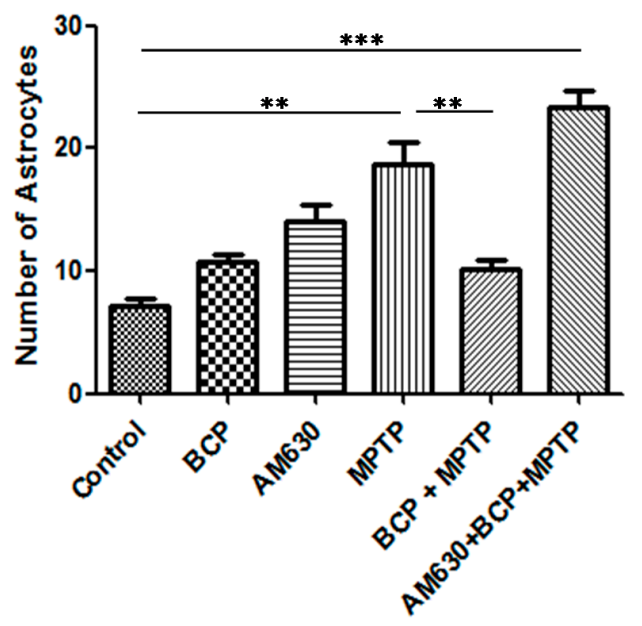

Figure 6. Effect of BCP on MPTP-induced astrocyte activation in the mouse SNpc. (A) Glial fibrillary acidic protein (GFAP)-IR astrocytes in mouse SNpc. Scale bar: $200 \mu \mathrm{m}$. (B) Stereological cell counts of GFAP-IR neurons. The data are presented as the mean \pm SEM of six individual experiments. ${ }^{* *} p<0.01$, CTL vs. MPTP treatment. ${ }^{* *} p<0.01$, MPTP treatment vs. BCP + MPTP treatment. ${ }^{* * *} p<0.001$, CTL vs. AM630 + BCP + MPTP treatment.

A

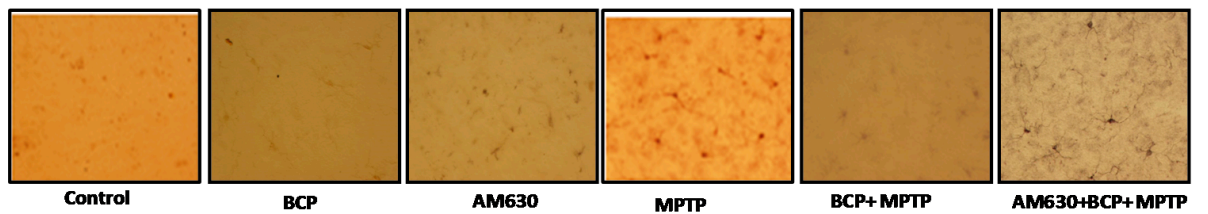

B

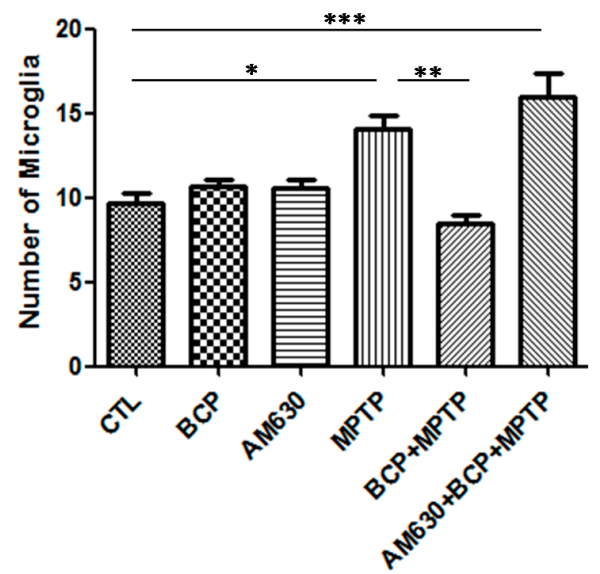

Figure 7. Effect of BCP on MPTP-induced microglia activation in the mouse SNpc. (A) Ionized calcium-binding adapter molecule-1 (IBA-1)-IR microglia in mouse SNpc. Scale bar: $200 \mu \mathrm{m}$. (B) Stereological cell counts of IBA-1-IR microglia. The data are presented as the mean \pm SEM of six individual experiments. ${ }^{*} p<0.05, \mathrm{CTL}$ vs. MPTP treatment. ${ }^{* *} p<0.01$, MPTP vs. BCP + MPTP treatment. ${ }^{* * *} p<0.001, \mathrm{CTL}$ vs. AM630 + BCP + MPTP treatment. 
Treatment with $10 \mathrm{mg} / \mathrm{kg} \mathrm{BCP} \mathrm{(10} \mathrm{mg/kg,} \mathrm{i.p.)} \mathrm{suppressed} \mathrm{the} \mathrm{MPTP-induced} \mathrm{increase} \mathrm{in}$ GFAP-IR cells and IBA-1-IR cells by 84.5 and $66.2 \%$, respectively, $(p<0.01)$ compared with the effects of MPTP treatment alone. The protective effect of $\mathrm{BCP}$ against astrocyte activation and microglia was fully reversed by pre-treating with $3 \mathrm{mg} / \mathrm{kg}$ AM630. Systemic administration of BCP alone not significantly affect the numbers of GFAP-IR or IBA-1-IR cells $(p<0.05$ compared with that of the control mice) (Figures 6 and 7).

Regarding the effect of $\mathrm{BCP}$ on astrocyte and microglia activation in the striatum, markedly activated astrocytes (Figure 8) and microglia (Figure 9) were observed in the mice that were administered MPTP (30 mg $/ \mathrm{kg}$, i.p.), as evidenced by a significant increase in GFAP-IR cell numbers (257\% compared with that of the control mice) and IBA-1-IR cell numbers (97.4\% compared with that of the control mice). Treatment with $10 \mathrm{mg} / \mathrm{kg}$ BCP suppressed the MPTP-induced increase in GFAP-IR cell numbers and IBA-1-IR cell numbers by $323.5 \%$ and $32 \%$, respectively, $(p<0.01)$ compared with the effects of MPTP treatment alone. The protective effect of BCP against astrocyte and microglia activation was fully reversed by pretreatment with $3 \mathrm{mg} / \mathrm{kg}$ AM630. Systemic administration of BCP alone did not significantly affect the number of GFAP-IR or IBA-1-IR cells (Figures 8 and 9).

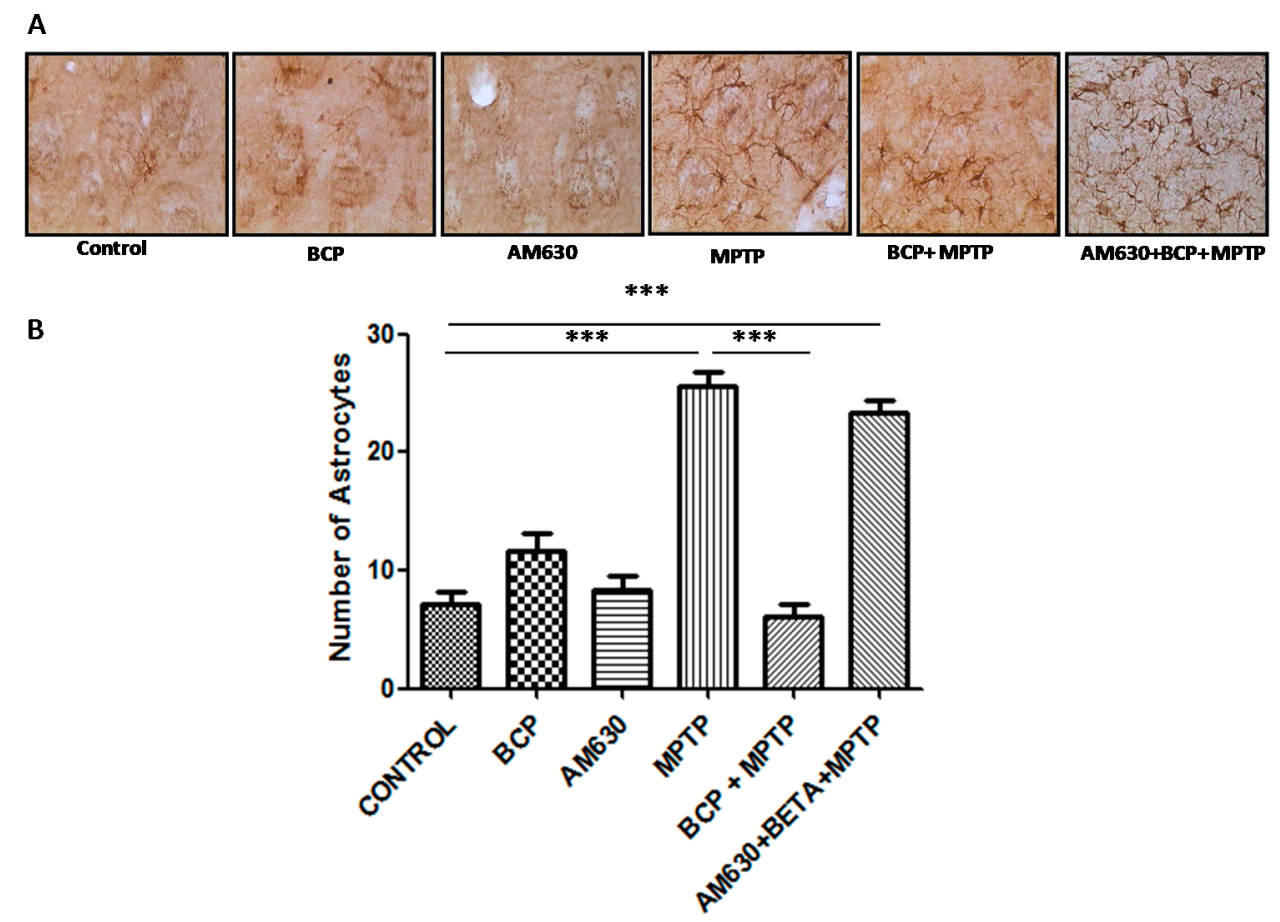

Figure 8. Effect of BCP on MPTP-induced astrocyte activation in the mouse STR. (A) Glial fibrillary acidic protein (GFAP)-IR astrocytes in mouse STR. Scale bar: $200 \mu \mathrm{m}$. (B) Stereological cell counts of GFAP-IR astrocyte. The data are presented as mean \pm SEM of six individual experiments. ${ }^{* * *} p<0.001$, CTL vs. MPTP. ${ }^{* * *} p<0.001$, MPTP vs. BCP+ MPTP. ${ }^{* * *} p<0.001$, CTL vs. AM630 + BCP + MPTP treatment. 
A

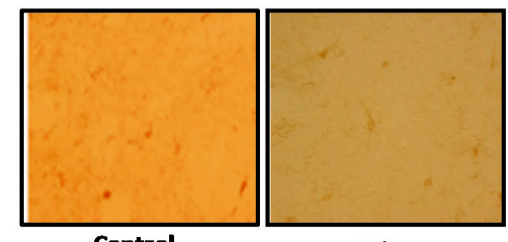

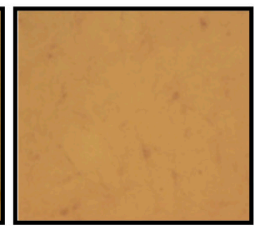

AM630

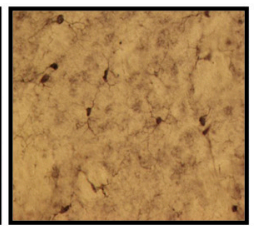

MPTP

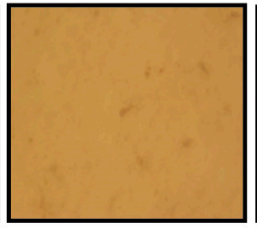

BCP+ MPTP

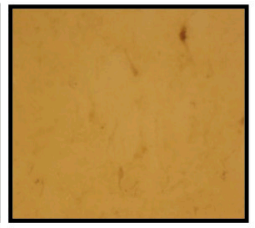

AM630+BCP+MPTP

B

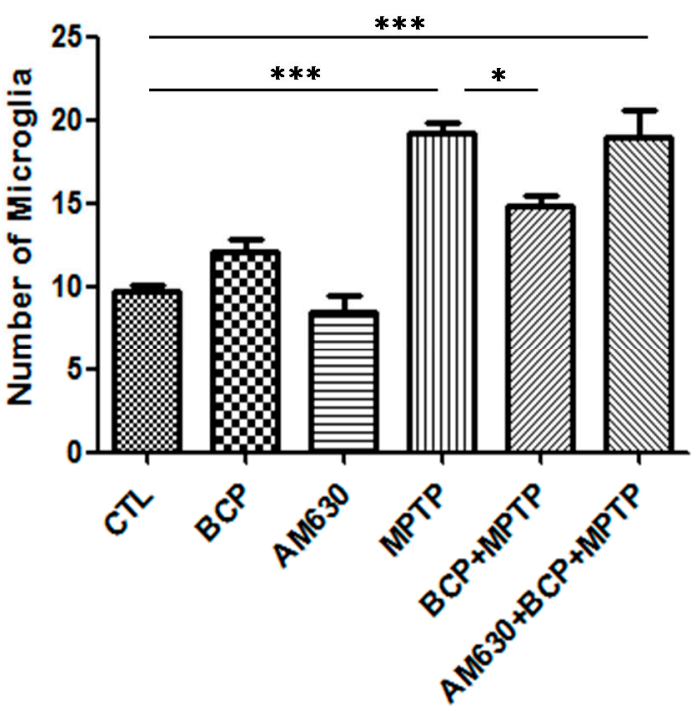

Figure 9. Effect of BCP on MPTP-induced microglia activation in the mouse STR. (A) Ionized calcium-binding adapter molecule-1 (IBA-1)-IR microglia in mouse STR. Scale bar: $200 \mu \mathrm{m}$. (B) Stereological cell counts of IBA-1-IR microglia. The data are presented as mean \pm SEM of six individual experiments. ${ }^{* *} p<0.001$, CTL vs. MPTP. ${ }^{*} p<0.05$, MPTP vs. BCP + MPTP. ${ }^{* *} p<0.001$, CTL vs. AM630 + BCP + MPTP treatment.

\section{4. $\beta$-Caryophyllene Inhibits the Levels of Inflammatory Cytokines in the Nigrostriatal System}

Basal protein levels of IL-6 $(30.6 \pm 1.1 \mathrm{pg} / \mathrm{mL}$ in the SN and $19.8 \pm 1.8 \mathrm{pg} / \mathrm{mL}$ in the STR), IL- $1 \beta(1119.0 \pm 255.8 \mathrm{pg} / \mathrm{mL}$ in the $\mathrm{SN}$ and $995.8 \pm 194.1 \mathrm{pg} / \mathrm{mL}$ in the STR $)$ and TNF- $\alpha$ $(2270.0 \pm 223.6 \mathrm{pg} / \mathrm{mL}$ in the SN and $2039.0 \pm 346.8 \mathrm{pg} / \mathrm{mL}$ in the STR) were measured by the Luminex MagPix cytokine assay specific for mice (Figure 10). In mice treated with MPTP (30 mg/kg, i.p.), IL-6 $(36.9 \pm 1.7 \mathrm{pg} / \mathrm{mL}$ in the SN), IL-1 $\beta(2207 \pm 326.1 \mathrm{pg} / \mathrm{mL}$ in the SN) and TNF- $\alpha(2826 \pm 149.5 \mathrm{pg} / \mathrm{mL}$ in the $\mathrm{SN}$ ) protein levels in the substantia nigra increased significantly when compared with those of the control mice (Figure 10).

In mice treated with $\mathrm{BCP}(10 \mathrm{mg} / \mathrm{kg}$, i.p. $)$ and MPTP, IL-6 $(26.9 \pm 3.9 \mathrm{pg} / \mathrm{mL})$ and IL-1 $\beta$ $(1261 \pm 192.5 \mathrm{pg} / \mathrm{mL})$ levels decreased but TNF- $\alpha$ levels $(2401 \pm 257 \mathrm{pg} / \mathrm{mL})$ remained the same compared to those of the control mice (Figure 10). Furthermore, the cytokine levels were unchanged in the striatum. Systemic administration of BCP alone did not significantly affect the levels of inflammatory cytokines. 
A

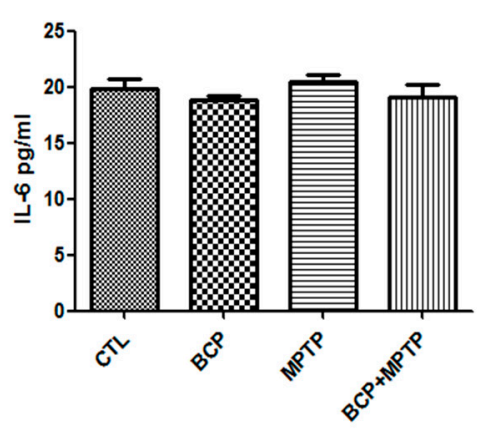

D

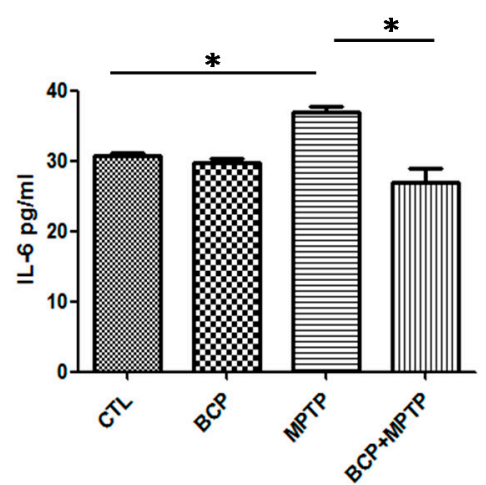

B

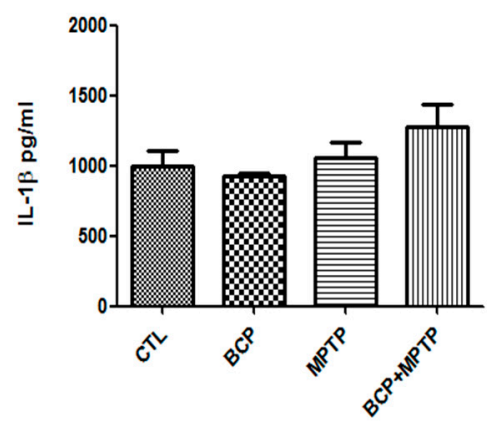

$\mathbf{E}$

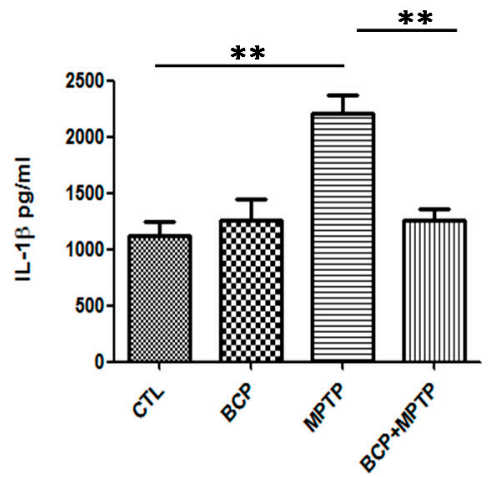

C

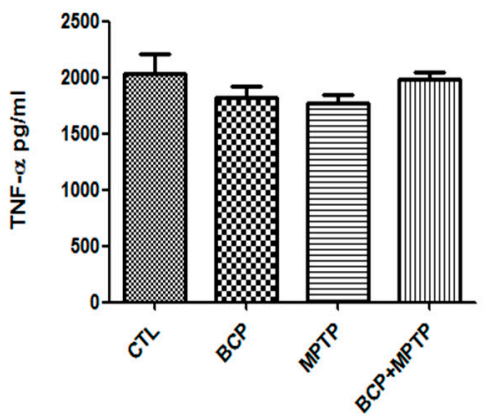

$\mathbf{F}$

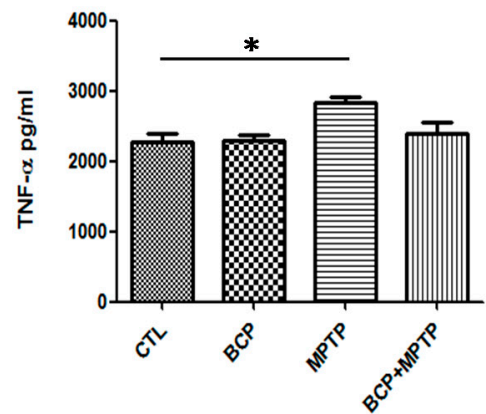

Figure 10. Protein levels of inflammatory cytokines in the nigrostriatal system. Graphsshowing the mean \pm SEM of three individual experiments of the protein levels of IL-6, IL-1 $\beta$, andTNF- $\alpha$ in the striatum $(\mathbf{A}-\mathbf{C})$ and the substantia nigra (D-F) determined using the indirect ELISA method. IL-6: $* p<0.05$, CTL vs. MPTP treatment. ${ }^{*} p<0.05$, MPTP treatment vs. BCP + MPTP treatment. IL-1 $\beta$ : $* * p<0.01$, CTL vs. MPTP treatment. ${ }^{* *} p<0.01$, MPTP treatment vs. BCP + MPTP treatment. TNF- $\alpha$ : * $p<0.05$, CTL vs. MPTP treatment.

\section{Discussion}

Various experimental evidence has shown that the endocannabinoid system is a target of pharmacological regulation for the treatment of PD [25]. In the pathology of PD, neuronal death and injury in the SNpc is caused by an inflammatory process largely mediated by the activation of glial cells. A very constant pathogenic condition in PD is oxidative damage leading to the degeneration of dopaminergic cells through the generation of reactive oxygen species (ROS), which ultimately potentiates the MPTP-induced neurotoxicity. It is well known that inflammatory mediators, such as nitric oxide (NO), chemokines and cytokines, play an important role in neuronal cell damage associated with glial cells, which is a crucial neuroinflammatory process involved in the initiation and development of neurodegenerative disorders such as PD [26]. Recently, it has been shown that the use of phytocannabinoid drugs can regulate the activation of glial cells and exert a neuroprotective effect against neuronal damage induced by MPTP, which constitutes an attractive framework for the development of neuroprotective agents against PD. A study published by Gertsch et al., showed that BCP selectively binds the CB2R [27]. Specifically, CB2R ligands, which have been shown to inhibit carrageen-induced mouse paw oedema [28], act on primary afferent neurons to inhibit nociception [29] and play a protective role in hepatic ischaemia reperfusion injury [30]. The use of $\mathrm{BCP}$ could offer this neuroprotective function without the psychotropic effects that occur when the CB1R is activated. This suggests that this selective CB2R agonist could potentially be a neuroprotective 
agent for neurodegenerative diseases, such as PD. Moreover, the endocannabinoid system modulates inflammatory responses through microglia and astroglia function, either by a receptor-dependent or an independent mechanism [31,32]. There are several reports that describe increased CB2R expression in the brain under pathological conditions, mainly in glial cells, which represents a potential therapeutic target for the inhibition of MPTP-induced neuronal damage [16,33,34]. In agreement with previous studies, MPTP administration in rodents produces a robust glia reaction, characterized by activated microglia and reactive astrocytes in the ventral midbrain. A similar reaction has been reported in the brain of PD patients [35]. As expected, in our experimental model, we observed enhanced immunoreactivity of GFAP-labelled astrocytes and IBA-1-labelled microglia in the SN and striatum of MPTP-treated mice, suggesting that reactive glial cells may play a key role in brain regions damaged by MPTP. In addition, we found that systemic administration of BCP significantly alleviated the MPTP-induced perturbed behavioural symptoms, improved the compromised motor coordination, protected against the degeneration of dopaminergic neurons, and suppressed the production of proinflammatory cytokines, including IL- 6 and IL-1 $\beta$, in the SN. In this sense, several lines of evidence suggest microglia-derived proinflammatory cytokines may be involved in nigrostriatal DA neuronal cell death. Studies of post-mortem PD subjects and models of induced PD show the presence of activated glial cells expressing proinflammatory cytokines, such as IL-1 $\beta$ and TNF- $\alpha$, in the SN. IL1- $\beta$ and TNF- $\alpha$ released from glial cells lead to intracellular death-related signalling pathways in the MPTP model of PD. This is comparable tofinding described that activated microglia-derived IL-1 $\beta$, IL-6 and TNF- $\alpha$ participated in DA neuronal cell death in an MPTP murine model of PD [36]. Additionally, our ELISA data showed that the activation of CB2R through the administration of BCP attenuated the MPTP-induced increases in IL-1 $\beta$ and IL- 6 in the SN. Price and colleagues showed that WIN55,212-2 prevents dopaminergic cell death induced by MPTP through the inhibition of microglial cells [15]. These results were reversed by treatment with the CB2R antagonist JTE in MPTP-treated mice, indicating the possible involvement of the microglia CB2R. This is in accordance with our observations that the CB2R antagonist AM630 inhibited the neuroprotective effect of the selective CB2R agonist BCP in MPTP-treated mice. These results demonstrate that it is possible that the activation of the $C B 2 R$, at least in part, participates in DA neuronal cell survival through the inhibition of glia activation in an MPTP murine model, although further studies are required to determine the underlying mechanisms. Moreover, the work done by Chung in 2010 demonstrated that the cytokine IL-1 $\beta$ directly participates in MPTP-induced cell death. In this work, the authors also demonstrated that the activation of the CB1R reduces the expression levels of IL-1 $\beta$ in the SN of MPTP-treated mice and that this neuroprotective action was reversed after the administration of specific antagonists to the CB1R and CB2R [6]. These results demonstrate that the activation of cannabinoid receptors can induce a phenotype change of M1 (IFN- $\gamma$, TNF- $\alpha$ and IL-2) to M2 (IL- 4 and IL-5) through a CB2 receptor-dependent mechanism mediated by anti-inflammatory actions, which can contribute to the neuroprotective effect [34]. An important cytokine in the establishment of the M2 phenotype is IL-10 [37,38]. Anandamide treatment induced an increase in the production of IL-10, mediated by the $\mathrm{CB} 2 \mathrm{R}$, as determined by the fact that blocking this receptor with a specific antagonist (SR2SR145228) reversed this effect. Additionally, use of the CB2R specific agonist JWH-133 produced similar effects as the AEA treatment.

During an inflammatory process astrocytes and microglia cells, in addition to secreting mediators of inflammation, such as IL- 6 , IL- $1 \beta$, TNF- $\alpha$, nitric oxide and reactive oxygen species that exert neurotoxic effects during pathological states [39], which can contribute significantly to the neurodegenerative process underlying PD [40,41]. In addition, these cells are able to release endocannabinoids to combat various neuropathological conditions [42] and traumatic CNS lesions [43].These neuroinflammatory processes require a delicate balance between the production of pro- and anti-inflammatory cytokines [44] so that inflammation is maintained within appropriate limits.

Many studies have reported that the activity of neurotrophic factors could prevent neurodegenerative disease [45,46]. In particular, glial cell line-derived neurotrophic factor (GDNF) 
is associated with astrocyte activation in $\mathrm{PD}[47,48]$. These findings suggest that astroglia activation might be beneficial for preventing PD pathologies through the production of neurotrophic factors, such as GDNF and ciliaryneurotrophic factor (CNTF). Recent research also has suggested that the expression of transient receptor potential vanilloid 1 in astrocytes is involved in neuroprotection in PD through the endogenous production of CNTF [49].

Although MPTP causes pathophysiological alterations in mice similar to those reported in idiopathic PD, this neurotoxin produces transient hypokinetic behaviour and inconsistent motor deficits that disappear within a few $\mathrm{d}$ of its administration [50-55]. One of the important causes of motor dysfunction induced by MPTP is decreased levels of DA in the SN and STR, which is mainly due to a lack of DA synthesis and storage in dopaminergic nerve endings [56]. The connection between the SNpc and the STR is critical for producing controlled and coordinated movement. A decrease in the levels of dopamine in this circuit results in abnormal nerve-firing patterns within the brain that cause uncontrolled and abnormal movements. Von Bohlen (2005), reported that the decrease in dopamine synthesis and storage in the dopaminergic nerve endings causes motor dysfunction in PD, while MPTP-induced TH reduction in the SNpc and STR is correlated with motor dysfunction [57,58]. To reveal behavioural correlates to MPTP-induced lesions, we used the gait, beam and pole performance tests [59]. Our results showed that BCP improved the abnormal behaviours in MPTP-treated mice, as manifested by the observation of a reduced total time required to climb down the pole, prolonged latent periods in the rotarod test, and increased vertical movements. The involvement of the CB2 receptor in the regulation of emotional behaviour suggests that this receptor could be an important therapeutic target for the treatment of anxiety and depressive disorders. In this sense, our results from the pole test showed that animals can generate pessimistic or dangerous thoughts. This was determined because mice treated with BCP showed considerably decreased of the fear caused by the pole height; the animals were very confident at the time of the test, which resulted in decreased time required to perform the test [60]. It is known that the modulation of CB2 receptor activation leads to increased levels of endocannabinoids, such as 2-AG and AEA, which can induce optimistic behaviour in mice. These effects of BCP were observed at a $10 \mathrm{mg} / \mathrm{kg}$ dose administered both orally and intraperitoneally. Based on the present results, we suggest that BCP may serve as a therapeutic agent for the alleviation of motor dysfunction by preventing dopaminergic neuronal damage.

However, one of the limitations of this study was that the dopamine levels were not assessed in the striatum and substantia nigra. In the animal studies, the endocannabinoid system has been reported to activate the dopaminergic system and to increase the availability of DA in the striatum. It is known that the DA neurons are key neurotransmitters that play a role in regulating growth, maintenance, and synaptic plasticity.

\section{Materials and Methods}

\subsection{Animals}

All experiments were carried out using male C57BL/6J mice (25-30 $\mathrm{g}$ of body weight) that were maintained under a 12:00 $\mathrm{h}$ light-dark cycle with food and water available ad libitum. The animals were obtained from Harlan Laboratories (Mexico City). All animal handling and experimentation strictly followed the Guidelines for Care and Use of Laboratory Animals published by the National Institutes of Health and the Guidelines of the Mexican Law of Animal Protection. Animal care and experimental procedures were in accordance with the Mexican Official Norms NOM-062-ZOO-1999 and NOM-033-ZOO-1995. All experimental procedures were approved by the research and ethics committees of the University of Guadalajara in Mexico. We minimized the number of mice used and their suffering or pain as much as possible. 


\subsection{Drug Administration Schemes}

Animals were randomly divided into four groups ( $n=6 /$ group). The first group of mice was saline-treated and served as a control group. The second group of mice was treated with MPTP following the subchronic scheme, which consisted of MPTP hydrochloride ( $30 \mathrm{mg} / \mathrm{kg}$, i.p.; Sigma-Aldrich, St. Louis, MO, USA) being administered daily for five consecutive days. The MPTP administration conditions and dosage were selected based on previous studies [61] in which dopamine depletion, apoptosis, inflammatory response, and oxidative damage were demonstrated in mice subjected to MPTP under the same experimental conditions. The third group of mice was treated with $\mathrm{BCP}(10 \mathrm{mg} / \mathrm{kg}$, i.p.) for five d. The fourth group of mice was pretreated with BCP for five $\mathrm{d}$, and one day after the last administration of BCP, the animals were treated with MPTP ( $30 \mathrm{mg} / \mathrm{kg}$, i.p.) for 5 consecutive days. The fifth group of mice received an administration of the CB2R antagonist AM630 (3 mg/kg, i.p., SML0327 Sigma-Aldrich) $30 \mathrm{~min}$ prior to an injection of another CB2R agonist, BCP. The control mice were injected with either a CB2 agonist and an antagonist alone or a vehicle. The animals were sacrificed 3 days after treatment was completed. To evaluate the effects of $\mathrm{BCP}$ administered orally, a group of animals was administered BCP $(10 \mathrm{mg} / \mathrm{kg})$ through an oral gavage for 5 consecutive days, and one day after the last administration of $\mathrm{BCP}$, the animals were treated with MPTP (30 mg/kg, i.p.) for 5 consecutive days.

\subsection{Behavioural Studies}

Behavioural tests were conducted three days after the last administration of each treatment.

\subsubsection{Pole Test}

Bradykinesia is measured by determining the amount of time it takes an animal to turn around and fully descend a pole according to a method described by Matsuura et al. (1997). Mice were first acclimated to the pole $(1 \mathrm{~cm}$ diameter, $50 \mathrm{~cm}$ height) in 10 trials, with each trial being separated by $120 \mathrm{~s}$. In the first trial, the animals were limited to $300 \mathrm{~s}$, and subsequent trials were limited to a $120 \mathrm{~s}$ maximum time limit. The three best scores were averaged for each mouse [62,63].

\subsubsection{Gait Test}

The gait test was performed according to the method established by Fernagut et al. The apparatus was $7 \mathrm{~cm}$ wide, $12 \mathrm{~cm}$ high and $60 \mathrm{~cm}$ long, finished in a dark box, and placed on an interchangeable part [64]. The forepaw of the subject mouse was wet with non-toxic blue ink, and the mouse was placed at the opposite end of the runway, which was covered with a strip of paper $(7 \mathrm{~cm}$ wide and $60 \mathrm{~cm}$ long). The stride length of the forelimb was measured manually as the distance between two forepaw prints. The three longest strides were measured. The first, second, and last paw prints were excluded because the velocity changed during the run.

\subsubsection{Beam Test}

This test uses a device that the mice escalate consisting of a 1-metre long acrylic beam placed at a 15-degree angle. The test mice were placed at the upper end of the beam, which was the box-home stimulus. Initially, the mice were trained to climb a beam that was $12-\mathrm{mm}$ wide for two d prior to beginning the management schemes; the test was initiated by changing the width of the beam to 6-mm wide. Mice were placed at the bottom of the beam and allowed to walk to reach the upper end while recording the time it took to arrive, with a maximum limit of $120 \mathrm{~s}$. After $120 \mathrm{~s}$, if the mouse had not reached its box-home manually, it was removed and placed in its box and received a rating of $120 \mathrm{~s}$. The results are expressed as the average total time (s) it took for the mice from each experimental treatment group to run the test. 


\subsection{Measurement of the IL-1 $\beta$, TNF- $\alpha$ and IL-6 Cytokines}

Analyte levels in cerebral homogenateswere measured using a commercially available Luminex MagPix cytokine (Bio-Rad, Hercules, CA, USA) assay specific for mice according to the manufacturer's instructions. The MagPix assay uses a red LED instead of a laser to excite the dyes in the beads $(6.5-\mu \mathrm{m}$ magnetic beads) for the identification of specific analytes and a green LED to excite the reporter ligand. Acquisition of the fluorescent signal was achieved by a CCD imager. The concentration of the analytes was determined using Bio-Plex ${ }^{\circledR 200}$ System and Bio-Plex ${ }^{\mathrm{TM}}$ Human Cytokine Standard 27-Plex, Group I (Bio-Rad). The assays were run in triplicateof three individual experimentsand the concentrations are expressed in $\mathrm{pg} / \mathrm{mL}$ based on a standard curve.

\subsection{Immunohistochemistry of Tyrosine Hydroxylase, GFAP and Iba}

Three days after the last treatment was administered, the mice ( $n=5$ per group) were anaesthetized (100 mg/ $\mathrm{kg}$ ketamine and $15 \mathrm{mg} / \mathrm{kg}$ xylazine, i.p.) and an intracardiac perfusion was performed with $0.1 \mathrm{M}$ PBS solution followed by $4 \%$ paraformaldehyde. After the perfusion, the brains were removed, kept in fixative solution for $24 \mathrm{~h}$, and subsequently washed 3 times with $0.1 \mathrm{M}$ PBS. Coronal $35-\mu \mathrm{m}$ sections were sliced on a vibratome (Leica VT1000E; Leica Microsystems, Wetzlar, Germany) to obtain the substantia nigra pars compacta (SNpc) and striatum (STR) regions. For morphological analysis of the STR and SNpc, coronal slices were cut at the bregma and $-3.3 \mathrm{~mm}$ from the bregma, respectively, according to the protocol provided by Paxinos and Franklin [65]. Six tissues were collected from each individual brain, with $175 \mu \mathrm{m}$ between each slice. According to the coordinates mentioned above, slices were selected at the same level in all animals to obtain a uniform analysis using the basic principle of fractionation from the caudal face area. Analysis of the results was performed to obtain the average number of marker-positive cells per field $(445-\mu \mathrm{m})$ at $40 \times$ magnification cells.

\subsection{Tyrosine Hydroxylase Assessment}

Samples were rinsed in 0.1 M PBS and then incubated in pre-warmed sodium citrate buffer $(\mathrm{pH}=6)$ for $10 \mathrm{~min}$. Next, the samples were washed three times with $0.1 \mathrm{M}$ PBS and then incubated with $1 \%$ hydrogen peroxide to block endogenous peroxidase staining. The slices were then washed first with $0.3 \%$ Triton X-100 in 0.1 PBS, followed by an additional two washes with $0.1 \%$ Triton $\mathrm{X}-100$ in 0.1 PBS. The samples were then incubated with $10 \%$ goat serum and $0.1 \%$ Triton $\mathrm{X}-100$ in $0.1 \mathrm{PBS}$ for $45 \mathrm{~min}$, followed by incubation for $72 \mathrm{~h}$ at $4{ }^{\circ} \mathrm{C}$ in the same buffer solution containing a tyrosine hydroxylase antibody (Ab152 Merck Millipore, Billerica, MA, USA). The samples were then washed $(4 \times 5 \mathrm{~min})$ in $0.1 \mathrm{M}$ PBS and incubated for $2 \mathrm{~h}$ at room temperature in the dark with an anti-rabbit IgG (BA1000, Vector Labs, Peterborough, UK) antibody at a dilution 1:500. An Elite $\mathrm{ABC}$ kit (Vector, PK6000) system was applied in the dark at a dilution of 1:200. The samples were detected with 3'3 diaminobenzidine (DAB kit, Vector Labs, Peterborough, UK). To determine the $\mathrm{TH}$-immunohistochemistry in the striatum, the sections that were $-3.3 \mathrm{~mm}$ relative to the bregma were selected to quantify the optical densities of the TH-immunoreactive fibres according to a previously described method [56]. TH-immunoreactive fibre density was measured in $100 \times 100 \mu \mathrm{m}$ square images of the striatum using an image analyser (Multiscan, Fullerton, CA, USA).

\subsection{GFAP and Iba Assessment}

Other tissue sections were processed to identify astrocyte and microglial cells. To identify astrocytes immunocytochemically, washes and incubations were performed on free-floating tissue sections while being moderately shaken. Briefly, tissue sections were incubated in $1 \%$ hydrogen peroxide to block endogenous peroxidase staining. Next, the slices were washed $(4 \times 5 \mathrm{~min})$ with 0.1 Triton X-100 in 0.1 PBS and then incubated for 45 min with 0.1 Triton X-100 in 0.1 PBS and 10\% goat serum. The slices were incubated in this same buffer overnight at $4{ }^{\circ} \mathrm{C}$ with an anti-glial fibrillary acidic protein (GFAP) polyclonal antibody (DAKO, Glostrup, Denmark) at a dilution of 1:400 and 
an anti-rabbit IgG secondary antibody (BA1000, Vector Labs). Then, complex incubation using the Elite ABC kit (Vector, PK6000) was performed in the dark for $2 \mathrm{~h}$ at a dilution 1:200. After being washed with 0.1 M PBS, the tissue sections were detected with 3'3-diaminobenzidine.

Histochemical staining of microglia was performed as follows: To inhibit peroxidase activity, sections were incubated for $20 \mathrm{~min}$ with $1 \% \mathrm{H}_{2} \mathrm{O}_{2}$. Tissues were rinsed in $0.1 \mathrm{M} \mathrm{PBS}(4 \times 5 \mathrm{~min})$ and incubated for $45 \mathrm{~min}$ in $0.1 \mathrm{M}$ PBS and $10 \%$ goat serum. They were then incubated overnight at $4^{\circ} \mathrm{C}$ with lectin from Bandeiraea BS-1.

\section{Statistical Analysis}

Statistical analysis was performed using GraphPad Prism5 software (GraphPad Software, Inc., La Jolla, CA, USA). Data are expressed as the means \pm SD. The multiple comparison one-way analysis of variance and Tukey's HSD post hoc tests were used for statistical analysis. $p$-values $\leq 0.05$ were considered statistically significant.

Acknowledgments: We thank PROSNI (University of Guadalajara) and the Center for Biomedical Research of the Occident (CIBO) IMSS, for financial support. The authors acknowledge Castañedad Achutigui F., for the implementation of the Immunohistochemistry of Tyrosine Hydroxylase, GFAP and Iba.

Author Contributions: J.M.V.-P. and M.E.F.-S. conceived and designed the experiments, and wrote and revised the paper; R.E.G.-C. and J.G. analyzed the data and discussion; V.C.-H., E.V.-V. and C.B.-Z. contributed reagents/materials/analysis tools and revised the paper; R.I.L.-R. and A.C.-E. analyzed the data.

Conflicts of Interest: The authors declare no conflict of interest.

\section{Abbreviations}

$\begin{array}{ll}\text { PD } & \text { Parkinson's disease } \\ \text { BCP } & \beta \text {-caryophyllene } \\ \text { CB1R } & \text { type 1 cannabinoid receptor } \\ \text { CB2R } & \text { type 2 cannabinoid receptor } \\ \text { MPTP } & \text { 1-methyl-4-phenyl-1,2,3,6-tetrahydropyridine } \\ \text { GFAP } & \text { glial fibrillary acidic protein } \\ \text { TH } & \text { tyrosine hydroxylase } \\ \text { CNS } & \text { central nervous system } \\ \text { NO } & \text { nitric oxide } \\ \text { ROS } & \text { oxygen species } \\ \text { GDNF } & \text { line-derived neurotrophic factor (GDNF) } \\ \text { CNTF } & \text { ciliary neurotrophic factor } \\ \text { SNpc } & \text { substantia nigra pars compacta } \\ \text { STR } & \text { striatum }\end{array}$

\section{References}

1. Nutt, J.G.; Wooten, G.F. Diagnosis and initial management of Parkinson's disease. N. Engl. J. Med. 2005, 353, 1021-1027. [CrossRef] [PubMed]

2. Tan, E.K.; Jankovic, J. Genetic testing in Parkinson disease: Promises and pitfalls. Arch. Neurol. 2006, 63, 1232-1237. [CrossRef] [PubMed]

3. Miller, N.; Noble, E.; Jones, D.; Burn, D. Hard to swallow: Dysphagia in Parkinson's disease. Age Ageing 2006, 35, 614-618. [CrossRef] [PubMed]

4. Dexter, D.T.; Jenner, P. Parkinson disease: From pathology to molecular disease mechanisms. Free Radic. Biol. Med. 2013, 62, 132-144. [CrossRef] [PubMed]

5. Gao, H.M.; Hong, J.S.; Zhang, W.; Liu, B. Distinct role for microglia in rotenone-induced degeneration of dopaminergic neurons. J. Neurosci. 2002, 22, 782-790. [PubMed]

6. Chung, Y.C.; Kim, S.R.; Jin, B.K. Paroxetine prevents loss of nigrostriatal dopaminergic neurons by inhibiting brain inflammation and oxidative stress in an experimental model of Parkinson's disease. J. Immunol. 2010, 185, 1230-1237. [CrossRef] [PubMed] 
7. Mogi, M.; Harada, M.; Narabayashi, H.; Inagaki, H.; Minami, M.; Nagatsu, T. Interleukin (IL)-1 beta, IL-2, IL-4, IL-6 and transforming growth factor-alpha levels are elevated in ventricular cerebrospinal fluid in juvenile parkinsonism and Parkinson's disease. Neurosci. Lett. 1996, 211, 13-16. [CrossRef]

8. Hirsch, E.C.; Hunot, S.; Damier, P.; Faucheux, B. Glial cells and inflammation in Parkinson's disease: A role in neurodegeneration? Ann. Neurol. 1998, 44, S115-S120. [CrossRef] [PubMed]

9. Ferger, B.; Leng, A.; Mura, A.; Hengerer, B.; Feldon, J. Genetic ablation of tumor necrosis factor-alpha (TNF-alpha) and pharmacological inhibition of TNF-synthesis attenuates MPTP toxicity in mouse striatum. J. Neurochem. 2004, 89, 822-833. [CrossRef] [PubMed]

10. Pott-Godoy, M.C.; Tarelli, R.; Ferrari, C.C.; Sarchi, M.I.; Pitossi, F.J. Central and systemic IL-1 exacerbates neurodegeneration and motor symptoms in a model of Parkinson's disease. Brain 2008, 131, 1880-1894. [CrossRef] [PubMed]

11. Chung, Y.C.; Bok, E.; Huh, S.H.; Park, J.Y.; Yoon, S.H.; Kim, S.R.; Kim, Y.S.; Maeng, S.; Park, S.H.; Jin, B.K. Cannabinoid receptor type 1 protects nigrostriatal dopaminergic neurons against MPTP neurotoxicity by inhibiting microglial activation. J. Immunol. 2011, 187, 6508-6517. [CrossRef] [PubMed]

12. Cabral, G.A.; Griffin-Thomas, L. Emerging role of the cannabinoid receptor CB2 in immune regulation: Therapeutic prospects for neuroinflammation. Expert Rev. Mol. Med. 2009, 11:e3. [CrossRef] [PubMed]

13. Zarruk, J.G.; Fernandez-Lopez, D.; Garcia-Yebenes, I.; Garcia-Gutierrez, M.S.; Vivancos, J.; Nombela, F.; Torres, M.; Burguete, M.C.; Manzanares, J.; Lizasoain, I.; et al. Cannabinoid type 2 receptor activation downregulates stroke-induced classic and alternative brain macrophage/microglial activation concomitant to neuroprotection. Stroke 2012, 43, 211-219. [CrossRef] [PubMed]

14. Concannon, R.M.; Okine, B.N.; Finn, D.P.; Dowd, E. Differential upregulation of the cannabinoid CB2 receptor in neurotoxic and inflammation-driven rat models of Parkinson's disease. Exp. Neurol. 2015, 269, 133-141. [CrossRef] [PubMed]

15. Price, D.A.; Martinez, A.A.; Seillier, A.; Koek, W.; Acosta, Y.; Fernández, E.; Strong, R.; Lutz, B.; Marsicano, G.; Roberts, J.L.; et al. WIN55,212-2, a cannabinoid receptor agonist, protects against nigrostriatal cell loss in the 1-methyl-4-phenyl-1,2,3,6-tetrahydropyridine mouse model of Parkinson's disease. Eur. J. Neurosci. 2009, 29, 2177-2186. [CrossRef] [PubMed]

16. Gómez-Gálvez, Y.; Palomo-Garo, C.; Fernández-Ruiz, J.; García, C. Potential of the cannabinoid CB $\mathrm{CB}_{2}$ receptor as a pharmacological target against inflammation in Parkinson's disease. Prog. Neuro Psychopharmacol. Biol. Psychiatry 2016, 64, 200-208. [CrossRef] [PubMed]

17. Opdyke, D.L. Monographs on fragrance raw materials. Food Cosmet. Toxicol. 1973, 11, 1011-1081. [CrossRef]

18. Lourens, A.C.; Reddy, D.; Baser, K.H.; Viljoen, A.M.; Van Vuuren, S.F. In vitro biological activity and essential oil composition of four indigenous South African Helichrysum species. J. Ethnopharmacol. 2004, 95, 253-258. [CrossRef] [PubMed]

19. Singh, G.; Marimuthu, P.; de Heluani, C.S.; Catalan, C.A. Antioxidant and biocidal activities of Carumnigrum (seed) essential oil, oleoresin, and their selected components. J. Agric. Food Chem. 2006, 54, 174-181. [CrossRef] [PubMed]

20. Kubo, I.; Chaudhuri, S.K.; Kubo, Y.; Sanchez, Y.; Ogura, T.; Saito, T.; Ishikawa, H.; Haraguchi, H. Cytotoxic and antioxidative sesquiterpenoids from Heterothecainuloides. Planta Med. 1996, 62, 427-430. [CrossRef] [PubMed]

21. Cornwell, P.A.; Barry, B.W. Sesquiterpene components of volatile oils as skin penetration enhancers for the hydrophilic permeant 5-fluorouracil. J. Pharm. Pharmacol. 1994, 46, 261-269. [CrossRef] [PubMed]

22. Agarwal, R.B.; Rangari, V.D. Phytochemical investigation and evaluation of anti-inflammatory and anti-arthritic activities of essential oil of Strobilanthus ixiocephala Benth. Indian J. Exp. Biol. 2003, 41, 890-894. [PubMed]

23. Baricevic, D.; Sosa, S.; Della, L.R.; Tubaro, A.; Simonovska, B.; Krasna, A.; Zupancic, A. Topical anti-inflammatory activity of Salvia officinalis L. leaves: The relevance of ursolic acid. J. Ethnopharmacol. 2001, 75, 125-132. [CrossRef]

24. Cho, J.Y.; Chang, H.J.; Lee, S.K.; Kim, H.J.; Hwang, J.K.; Chun, H.S. Amelioration of dextran sulfate sodium-induced colitis in mice by oral administration of $\beta$-caryophyllene, a sesquiterpene. Life Sci. 2007, 80, 932-939. [CrossRef] [PubMed]

25. Centonze, D.; Finazzi-Agrò, A.; Bernardi, G.; Maccarrone, M. The endocannabinoid system in targeting inflammatory neurodegenerative diseases. Trends Pharmacol. Sci. 2007, 28, 180-187. [CrossRef] [PubMed] 
26. Farina, C.; Aloisil, F.; Mein, E. Astrocytes are active players in cerebral innate immunity. Trends Immunol. 2007, 28, 138-145. [CrossRef] [PubMed]

27. Gertsch, J.; Leonti, M.; Raduner, S.; Racz, I.; Chen, J.Z.; Xie, X.Q.; Altmann, K.H.; Karsak, M.; Zimmer, A. Beta-caryophyllene is a dietary cannabinoid. Proc. Natl. Acad. Sci. USA. 2008, 105, 9099-9104. [CrossRef] [PubMed]

28. Iwamura, H.; Suzuki, H.; Ueda, Y.; Kaya, T.; Inaba, T. In vitro andin vivopharmacological characterization of JTE-907, a novel selective ligand for cannabinoid CB2 receptor. J. Pharmacol. Exp. Ther. 2001, 296, 420-425. [PubMed]

29. Ibrahim, S.M.; Mix, E.; Böttcher, T.; Koczan, D.; Gold, R.; Rolfs, A.; Thiesen, H.J. Gene expression profiling of the nervous system in murine experimental autoimmune encephalomyelitis. Brain 2001, 124, 1927-1938. [CrossRef] [PubMed]

30. Batkai, S.; Osei-Hyiaman, D.; Pan, H.; El-Assal, O.; Rajesh, M.; Mukhopadhyay, P.; Hong, F.; Harvey-White, J.; Jafri, A.; Hasko, G.; et al. Cannabinoid-2 receptor mediates protection against hepatic ischemia/reperfusion injury. FASEB J. 2007, 21, 1788-1800. [CrossRef] [PubMed]

31. Ramírez, B.G.; Blázquez, C.; Gómez del Pulgar, T.; Guzmán, M.; de Ceballos, M.L. Prevention of Alzheimer's disease pathology by cannabinoids: Neuroprotection mediated by blockade of microglial activation. J. Neurosci. 2005, 25, 1904-1913. [CrossRef] [PubMed]

32. Walter, L.; Stella, N. Cannabinoids and neuroinflammation. Br. J. Pharmacol. 2004, 141, 775-785. [CrossRef] [PubMed]

33. Wotherspoon, G.; Fox, A.; McIntyre, P.; Colley, S.; Bevan, S.; Winter, J. Peripheral nerve injury induces cannabinoid receptor 2 protein expression in rat sensory neurons. Neuroscience 2005, 135, 235-245. [CrossRef] [PubMed]

34. Jean-Gilles, L.; Gran, B.; Constantinescu, C.S. Interaction between Cytokines, Cannabinoids and the Nervous System. Immunobiology 2010, 215, 606-610. [CrossRef] [PubMed]

35. Vila, M.; Jackson-Lewis, V.; Guegan, C.; Wu, D.C.; Teismann, P.; Choi, D.K.; Tieu, K.; Przedborski, S. The role of glial cells in Parkinson's disease. Curr. Opin. Neurol. 2001, 14, 483-489. [CrossRef] [PubMed]

36. Teismann, P.; Tieu, K.; Cohen, O.; Choi, D.K.; Wu, D.C.; Marks, D.; Vila, M.; Jackson-Lewis, V.; Przedborski, S. Pathogenic role of glial cells in Parkinson's disease. Mov. Disord. 2003, 18, 121-129. [CrossRef] [PubMed]

37. Moore, K.W.; O'Garra, A.; de Waal-Malefyt, R.; Vieira, P.; Mosmann, T.R. Interleukin-10. Annu. Rev. Immunol. 1993, 11, 165-190. [CrossRef] [PubMed]

38. Sieling, P.A.; Abrams, J.S.; Yamamura, M.; Salgame, P.; Bloom, B.R.; Rea, T.H.; Modlin, R.L. Immunosuppressive roles for IL-10 and IL-4 in human infection. In vitro modulation of T cell responses in leprosy. J. Immunol. 1993, 150, 5501-5510. [PubMed]

39. Suzumura, A.; Takeuchi, H.; Zhang, G.; Kuno, R.; Mizuno, T. Roles of glia-derived cytokines on neuronal degeneration and regeneration. Ann. N. Y. Acad. Sci. 2006, 1088, 219-229. [CrossRef] [PubMed]

40. Herrera, A.J.; Castano, A.; Venero, J.L.; Cano, J.; Machado, A. The single intranigral injection of LPS as a new model for studying the selective effects of inflammatory reactions on dopaminergic system. Neurobiol. Dis. 2000, 7, 429-447. [CrossRef] [PubMed]

41. Wu, D.C.; Jackson-Lewis, V.; Vila, M.; Tieu, K.; Teismann, P.; Vadseth, C.; Choi, D.K.; Ischiropoulos, H.; Przedborski, S. Blockade of microglial activation is neuroprotective in the 1-methyl-4-phenyl-1,2,3,6tetrahydropyridine mouse model of Parkinson disease. J. Neurosci. 2002, 22, 1763-1771. [PubMed]

42. Mechoulam, R.; Spatz, M.; Shohami, E. Endocannabinoids and neuroprotection. Sci. STKE 2002, 129, 1-6. [CrossRef] [PubMed]

43. Panikashvili, D.; Simeonidou, C.; Ben-Shabat, S.; Hanus, L.; Breuer, A.; Mechoulam, R. An endogenous cannabinoid (2-AG) is neuroprotective after brain injury. Nature 2001, 413, 527-531. [CrossRef] [PubMed]

44. Aste-Amezaga, M.; Ma, X.; Sartori, A.; Trinchieri, G. Molecular mechanisms of the induction of IL-12 and its inhibition by IL-10. J. Immunol. 1998, 160, 5936-5944. [PubMed]

45. Giralt, A.; Friedman, H.C.; Caneda-Ferron, B.; Urban, N.; Moreno, E.; Rubio, N.; Blanco, J.; Peterson, A.; Canals, J.M.; Alberch, J. BDNF regulation under GFAP promoter provides engineered astrocytes as a new approach for long-term protection in Huntington's disease. Gene Ther. 2010, 17, 1294-1308. [CrossRef] [PubMed] 
46. Houeland, G.; Romani, A.; Marchetti, C.; Amato, G.; Capsoni, S.; Cattaneo, A.; Marie, H. Transgenic mice with chronic NGF deprivation and Alzheimer's disease-like pathology display hippocampal region-specific impairments in short- and long-term plasticities. J. Neurosci. 2010, 30, 13089-13094. [CrossRef] [PubMed]

47. Hwang, I.K.; Yoo, K.Y.; Kim, D.W.; Lee, B.H.; Kang, T.C.; Choi, S.Y.; Han, B.H.; Kim, J.S.; Won, M.H. Ischemia-related changes of glial-derived neurotrophic factor and phosphatidylinositol 3-kinase in the hippocampus: Their possible correlation in astrocytes. Brain Res. 2006, 1072, 215-223. [CrossRef] [PubMed]

48. Zhao, Q.; Gao, J.; Li, W.; Cai, D. Neurotrophic and neurorescue effects of echinacoside in the subacute MPTP mouse model of Parkinson's disease. Brain Res. 2010, 1346, 224-236. [CrossRef] [PubMed]

49. Nam, J.H.; Park, E.S.; Won, S.Y.; Lee, Y.A.; Kim, K.I.; Jeong, J.Y.; Baek, J.Y.; Cho, E.J.; Jin, M.; Chung, Y.C.; et al. TRPV1 on astrocytes rescues nigral dopamine neurons in Parkinson's disease via CNTF. Brain 2015, 138, 3610-3622. [CrossRef] [PubMed]

50. Heikkila, R.E.; Sonsalla, P.K. The MPTP-treated mouse as a model of parkinsonism: How good is it? Neurochem. Int. 1992, 20, 299S-303S. [CrossRef]

51. Fredriksson, A.; Eriksson, P.; Archer, T. MPTP-induced deficits in motor activity: Neuroprotective effects of the spintrapping agent, alpha-phenyl-tert-butyl-nitrone (PBN). J. Neural Transm. (Vienna) 1997, 104, 579-592. [CrossRef] [PubMed]

52. Rozas, G.; Lopez-Martin, E.; Guerra, M.J.; Labandeira-Garcia, J.L. The overall rod performance test in the MPTP-treated-mouse model of Parkinsonism. J. Neurosci. Methods 1998, 83, 165-175. [CrossRef]

53. Spooren, W.P.; Vassout, A.; Waldmeier, P.; Gentsch, C. Differences in pre- and post-synaptic sensitivity to apomorphine between saline and 1-methyl-4-phenyl-1,2,3,6-tetrahydropyridine-treated C57BL/6 mice as reflected in climbing activity. Eur. J. Pharmacol. 1998, 353, 1-4. [CrossRef]

54. Sedelis, M.; Schwarting, R.K.; Huston, J.P. Behavioral phenotyping of the MPTP mouse model of Parkinson's disease. Behav. Brain Res. 2001, 125, 109-125. [CrossRef]

55. Tillerson, J.L.; Caudle, W.M.; Reveron, M.E.; Miller, G.W. Detection of behavioral impairments correlated to neurochemical deficits in mice treated with moderate doses of 1-methyl-4-phenyl-1,2,3,6-tetrahydropyridine. Exp. Neurol. 2002, 178, 80-90. [CrossRef] [PubMed]

56. Kim, M.; Cho, K.H.; Shin, M.S.; Lee, J.M.; Cho, H.S.; Kim, C.J.; Shin, D.H.; Yang, H.J. Berberine prevents nigrostriatal dopaminergic neuronal loss and suppresses hippocampal apoptosis in mice with Parkinson's disease. Int. J. Mol. Med. 2014, 33, 870-878. [CrossRef] [PubMed]

57. Von-Bohlen Und Halbach, O. Modeling neurodegenerative diseases in vivo review. Neurodegener. Dis. 2005, 2, 313-320. [CrossRef] [PubMed]

58. Schintu, N.; Frau, L.; Ibba, M.; Garau, A.; Carboni, E.; Carta, A.R. Progressive dopaminergic degeneration in the chronic MPTPp mouse model of Parkinson's disease. Neurotox. Res. 2009, 16, 127-139. [CrossRef] [PubMed]

59. Tillerson, J.L.; Miller, G.W. Grid performance test to measure behavioral impairment in the MPTP-treated-mouse model of parkinsonism. J. Neurosci. Methods 2003, 123, 189-200. [CrossRef]

60. Kregiel, J.; Malek, N.; Popik, P.; Starowicz, K.; Rygula, R. Anandamide mediates cognitive judgement bias in rats. Neuropharmacology 2016, 101, 146-153. [CrossRef] [PubMed]

61. Kuroiwa, H.; Yokoyama, H.; Kimoto, H.; Kato, H.; Araki, T. Biochemical alterations of the striatum in an MPTP-treated mouse model of Parkinson's disease. Metab. Brain Dis. 2010, 25, 177-183. [CrossRef] [PubMed]

62. Matsuura, K.; Kabuto, H.; Makino, H.; Ogawa, N. Pole test is a useful method for evaluating the mouse movement disorder caused by striatal dopamine depletion. J. Neurosci. Methods 1997, 73, 45-48. [CrossRef]

63. Antzoulatos, E.; Jakowec, M.W.; Petzinger, G.M.; Wood, R.I. Sex differences in motor behavior in the MPTP mouse model of Parkinson's disease. Pharmacol. Biochem. Behav. 2010, 95, 466-472. [CrossRef] [PubMed]

64. Fernagut, P.O.; Diguet, E.; Labattu, B.; Tison, F. A simple method to measure stride length as an index of nigrostriatal dysfunction in mice. J. Neurosci. Methods 2002, 113, 123-130. [CrossRef]

65. Paxinos, G.; Franklin, K.B.J. The Mouse Brain in Stereotaxic Coordinates, 4th ed.; Academic Press: San Diego, CA, USA, 2013; pp. 31-231.

(C) 2017 by the authors. Licensee MDPI, Basel, Switzerland. This article is an open access article distributed under the terms and conditions of the Creative Commons Attribution (CC BY) license (http:/ / creativecommons.org/licenses/by/4.0/). 